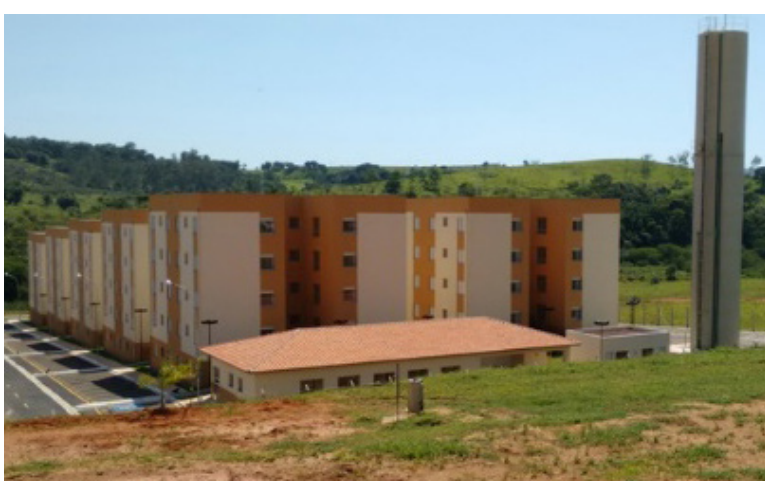

*Possui graduação em Engenharia Civil pela Universidade de Mogi das Cruzes (1998), é mestranda do IPT (Instituto de Pesquisas Tecnológicas do Estado de São Paulo).

\title{
PMCMV - Faixa 1: O que motiva as famílias a deixarem sua tão sonhada casa própria?
}

PMCMV - Zone 1: What motivates families to leave their sweet home?

Cintia Maria Velloso*

\section{Resumo}

$\mathrm{O}$ presente trabalho busca estudar as causas de abandono, venda e locação das unidades habitacionais dos condomínios verticalizados do programa "Minha Casa, Minha Vida", para famílias com renda de até três salários mínimos, no município de São José dos Campos. O estudo consiste no levantamento bibliográfico e nas entrevistas com os agentes envolvidos analisando a origem e o perfil socioeconômico dos beneficiários, assim como do processo de mudança e adaptação à vida em condomínio. Como resultado final será possível demonstrar que o PMCMV resolve parcialmente o problema do déficit habitacional, porém não isentam as famílias da situação de vulnerabilidade social, motivando-as, muitas vezes, a deixar sua tão sonhada casa própria.

Palavras-chave: Programa "Minha Casa Minha Vida"; Habitação de Interesse Social; São José dos Campos.

\section{Abstract}

The present work aims to study the causes of abandonment, sale and rental of the housing in the vertical condominiums among the program "Minha Casa, Minha Vida", for families with income up to three minimum wages, in the municipality of São José dos Campos. The study consists of a bibliographical survey and interviews with the agents involved, analyzing the origin and socioeconomic profile of the beneficiaries, as well as the process of change and adaptation to life in condominium. As a final result it will be possible to demonstrate that the PMCMV partially solves the problem of the housing deficit, but does not exempt the families from the situation of social vulnerability, often motivating them to leave their dream home.

Keywords: "Minha Casa Minha Vida" Program; Social Housing; São José dos Campos 


\section{Introdução}

A acarretou o problema urbano de difícil solução no Brasil, o déficit habitacional para a população de baixa renda.

Os primeiros movimentos significativos para enfrentar este desafio ocorreram com a criação do Banco Nacional de Habitação (BNH) e através da política habitacional subsidiada, descentralizada e diversificada do governo de Fernando Henrique Cardoso (FHC), no lançamento do Programa de Arrendamento Residencial (PAR), com subsídio dirigido à população, por meio do modelo de arrendamento ao invés da transferência de propriedade.

Esse movimento incentivou uma parte do setor imobiliário a se dedicar à produção para camadas de renda mais baixa e abriu, em 2009, o caminho para a modelagem do programa de produção em larga escala, do governo de Luiz Inácio Lula da Silva, o Programa Minha Casa Minha Vida (PMCMV).
Ele surgiu como um pacote habitacional disposto a reduzir o déficit habitacional brasileiro através da produção em grande escala, subsidiando moradias para famílias pobres e facilitando o financiamento habitacional para as demais faixas de renda; e a alavancar a economia, gerando empregos diretos e indiretos no setor da indústria da construção civil.

Esse desenho se apoiava nos dados quantitativos do déficit habitacional, e gerava em torno 7,2 milhões de moradias, sendo $90 \%$ concentradas na população com renda inferior a três salários mínimos.

A questão principal para definir essa modalidade de moradia estava na dificuldade dessas famílias possuírem índices de capacidade de comprometimento da renda que permitissem o acesso aos programas habitacionais do SFH e na ausência de restrições cadastrais, para afastar o risco do agente financeiro. Assim concluiu-se que a única 
maneira de garantir o acesso às moradias para essa população era através de utilização de subsídio direto de recursos federais, quase integral do FAR ou FDS, com isenção do seguro, independente de possuir ou não restrição cadastral, e que seriam pagos mediante prestações mensais durante 120 meses. Originando a modalidade PMCMV - Faixa 1.

Assim a ideologia do sonho da casa própria reassume como protagonista do PMCMV. Trazendo de volta a tradicional política de financiamento apoiada na posse, com foco na produção de uni- dades, sem definir critérios de qualidade de projetos, referências técnicas, nem articulação com os Planos Diretores Municipais que regulam as cidades.

Assim, o que se via era a construção desses empreendimentos em regiões cada vez mais periféricas, nas beiradas e franjas das cidades, ignorando totalmente a proposta do PlanHAB de uma política que pretendia uma grande diversidade de programas e produtos habitacionais, adequando os municípios às suas características demográficas e dinâmicas econômicas (Figura 1).

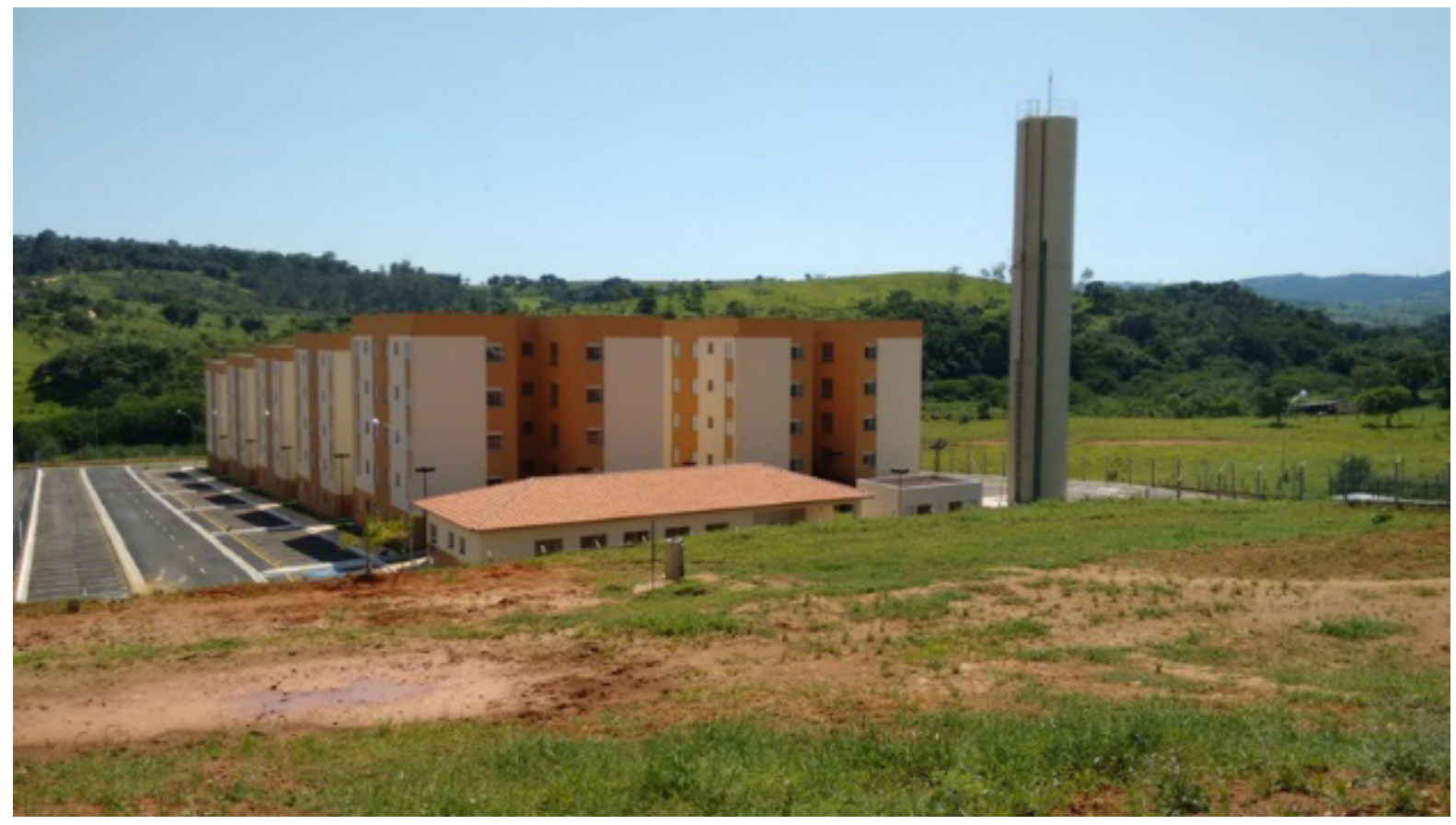

Figura 1. Conjunto Residencial Colinas 2 em São José dos Campos/SP. Fonte: CAIXA (2016) 
Rufino (2016) expõe que a habitação se apresenta como um produto padronizado, baseado na produção da propriedade privada em grandes condomínios, não levando em consideração as diferentes demandas e necessidades de habitação de interesse social, além das distintas características sociais e econômicas da população.

Essa iniciativa abriu novas possibilidades e expectativas para a política habitacional no Brasil, porém incorreu em falhas sensibilizadas na presente pesquisa, que são fundamentadas com a insatisfação das famílias beneficiárias que elevou a índices superiores a $20 \%$ o abandono, venda ou locação das unidades habitacionais desses empreendimentos.

Este artigo tem como objetivo compreender o porquê de um programa tão importante apresentar índices tão altos de insucesso, e levantar os principais impactos econômicos e sociais que dificultaram as famílias beneficiadas pelo PMCMV - Faixa 1 a se manterem nos condomínios verticais do estudo de caso, localizados no município de São José dos Campos.

\section{PMCMV - Faixa 1: dinâmica social para adaptação à nova moradia}

O município de São José dos Campos, situado a leste do Estado de São Paulo, onde foram analisados os estudos de casos, possuía em 2010 um déficit habitacional divulgado pela FJP de 21.910 domicílios, sendo aproximadamente $56 \%$ concentrados na faixa de renda de 0 a 3 salários mínimos (Figura 2).

\begin{tabular}{|l|c|}
\hline Faixa de Renda & Déficit \\
\hline sem rendimento & 506 \\
\hline 0 a 3 salários mínimos & 11.801 \\
\hline 3 a 6 salários mínimos & 3.206 \\
\hline 6 a 10 salários mínimos & 4.368 \\
\hline acima de 10 salários mínimos & 2.029 \\
\hline Total & $\mathbf{2 1 . 9 1 0}$ \\
\hline
\end{tabular}

Figura 2. Distribuição do déficit de São José dos Campos por faixa de renda (2010). Fonte: FJP (Adaptada pela autora)

Com o objetivo de reduzir esse déficit, em 2013 o município assinou o Termo de Adesão do PMCMV, tendo sido contratado desde então, conforme dados da CAIXA (2018), 12 empreendimentos para famílias de 0 a 3 salários mínimos, sendo em 11 condomínios e 01 loteamento, totalizando 4.195 unidades habitacionais em aproximadamente 03 anos (Figura 3). 
Cintia Maria Velloso

PMCMV - Faixa 1: O que motiva as famílias a deixarem sua tão sonhada casa própria?

\begin{tabular}{|c|l|l|c|l|}
\hline Qtde & Empreendimentos & Bairro - Região & UH's & Situação \\
\hline 1 & Res. Colônia Paraíso I & Parque dos Ipês - Região Sul & 244 & Entregue em jun/2015 \\
\hline 2 & Res. Colônia Paraíso II & Parque dos Ipês - Região Sul & 284 & Entregue em jun/2015 \\
\hline 3 & Res. Alto da Ponte & Alto da Ponte - Região Norte & 300 & Entregue em dez/2015 \\
\hline 4 & Res. Campos de São José II & Cajuru - Região Leste & 144 & Entregue em dez/2015 \\
\hline 5 & Conj. Res. Colinas 1 & Cajuru - Região Leste & 200 & Entregue em fev/2016 \\
\hline 6 & Conj. Res. Colinas 2 & Cajuru - Região Leste & 200 & Entregue em fev/2016 \\
\hline 7 & Res. Bom Retiro II & Novo Horizonte - Região Leste & 198 & Entregue em nov/2016 \\
\hline 8 & Res. Cajuru 1 & Cajuru - Região Leste & 288 & Entregue em dez/2016 \\
\hline 9 & Res. Cajuru 3 & Cajuru - Região Leste & 288 & Entregue em dez/2016 \\
\hline 10 & Pinheirinho dos Palmares & Pinheirinho - Região Sudeste & 1.461 & Entregue em dez/2016 \\
\hline 11 & Res. Mirante do Limoeiro 1 & Jd. Limoeiro - Região Oeste & 300 & Em execução \\
\hline 12 & Res. Mirante do Limoeiro 2 & Jd. Limoeiro - Região Oeste & 288 & Em execução \\
\hline & Total & $\mathbf{4 . 1 9 5}$ & \\
\hline
\end{tabular}

Figura 3. Empreendimentos do PMCMV - São José dos Campos. Fonte: CAIXA (2018) Elaborada pela autora.

Não podemos negar que a construção dessas unidades habitacionais ajudaram e muito a redução do déficit habitacional nesta faixa de renda no munícipio de São José dos Campos, porém cabe questionar qual foi a qualidade dessa redução, tendo em vista que os índices abandono, venda e locação desses imóveis vêm crescendo a cada dia.

Apesar dos incessantes avisos por parte da CAIXA e das técnicas sociais da Prefeitura de São José dos Campos de que a comercialização do imóvel, sem a respectiva quitação, caracteriza irregularidade por parte do beneficiário, conforme a lei 11.977/2009 do PMCMV, a cada vistoria realizada pelo poder público aparecem mais e mais casos de comercialização clandestina.
Conforme demonstra a figura 4, os altos índices de irregularidade, nos empreendimentos do estudo de caso, foram verificados junto à Gerência de Habitação da CAIXA, através do levantamento da quantidade de denúncias formais e de pesquisa direcionada aos síndicos dos empreendimentos PMCMV.

Para que se possa ter uma referência da representatividade deste índice, usamos como comparativo alguns empreendimentos da modalidade PMCMV - Entidades entregues em São Paulo, que apresentam um percentual bem abaixo, de aproximadamente 5\%.

A fim de analisar as trajetórias familiares e as experiências de como é viver nesses condomínios, 


\begin{tabular}{|l|c|c|c|c|}
\hline \multirow{2}{*}{ Empreendimentos } & \multirow{2}{*}{ UH's } & \multicolumn{3}{|c|}{ Qtde UH abandonadas, vendidas ou alugadas } \\
\cline { 3 - 5 } & & Ocorrências CAIXA & Informações Síndicos & $\%$ \\
\hline Res. Colônia Paraíso II & 284 & 69 & 86 & 30,28 \\
\hline Res. Alto da Ponte & 300 & 15 & 63 & 21 \\
\hline Conj. Res. Colinas 2 & 200 & 32 & 68 & 34 \\
\hline
\end{tabular}

Figura 4. Índice de abandono, venda e locação das UH's dos empreendimentos Colônia Paraíso II, Alto da Ponte e Colinas 2. Fonte: CAIXA e Pesquisa com os síndicos (mar/2018). Elaborada pela autora.

foram escolhidos três empreendimentos para estudo de caso: Residencial Colônia Paraíso II, Residencial Alto da Ponte e Conjunto Residencial Colinas 2 .

A metodologia de pesquisa aplicada procurou, com base na experiência vivenciada pelas famílias beneficiárias, caracterizá-las pela origem e perfil socioeconômico.

No decorrer da pesquisa a característica "origem" mostrou ser um fator importante nas causas de abandono, pois foi registrado que aproximadamente dois terços dos moradores originários de área de risco deixaram o empreendimento no decorrer desses poucos mais de 02 anos.

Esse percentual corresponde a quase $30 \%$ do total de unidades habitacionais, tendo em vista que Prefeitura de São José dos Campos optou por indicar na maioria dos empreendimentos o percentual máximo de $50 \%$ de famílias oriundas de área de risco, reassentamentos e/ou desabrigados, atendendo os critérios definidos na Portaria do Ministério das Cidades nº 595 de 18/12/2013.

Após análise dessas informações foi possível concluir que alguns resultados apresentados possuem ligação direta com as causas que tornaram a permanência nos condomínios um grande peso emocional, social e financeiro:

- A origem das famílias;

- Maior parte dos moradores na faixa etária economicamente ativa;

- Elevado índice de desemprego;

- Moradores com baixa renda familiar;

- Baixo índice educacional dos moradores.

Para substanciar os dados quantitativos e com o objetivo qualitativo de colher depoimentos e opiniões, trazendo uma visão mais "humana" das relações que essas famílias tiveram com a sua nova moradia, foram realizadas entrevistas junto aos síndicos e aos moradores do condomínio. 


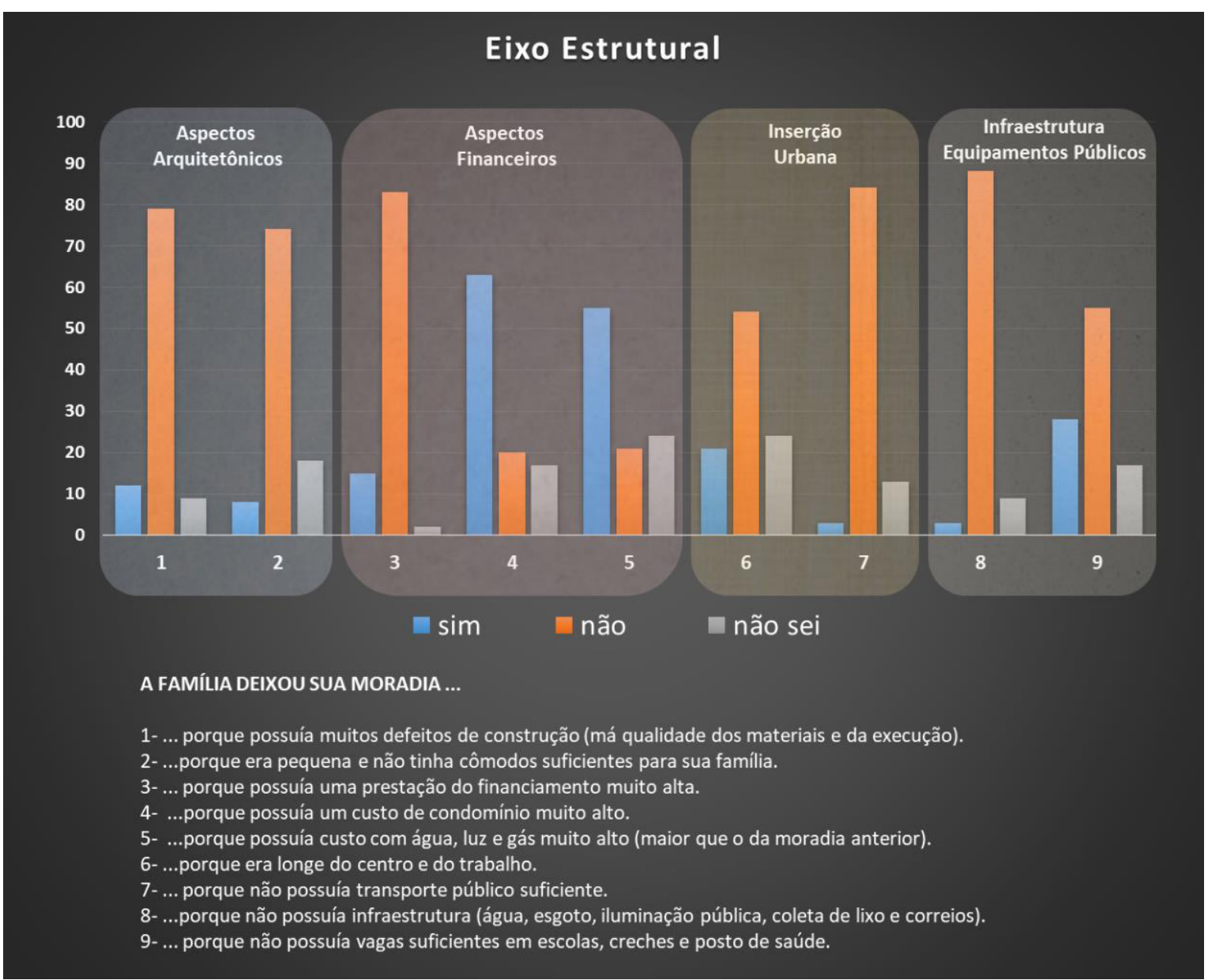

Figura 5. Eixo estrutural: influência dos aspectos arquitetônicos, aspectos financeiros, inserção urbana, infraestrutura e equipamentos públicos como causa de abandono, venda ou aluguel do imóvel dos empreendimentos Colônia Paraíso II, Alto da Ponte e Colinas 2. Fonte: Pesquisa com os síndicos (jun/2018). Elaborado pela autora.
Optou-se por adotar uma pesquisa por meio de escalas tipo Likert, que permite medir as percepções e conhecer o grau de conformidade do entrevistado com qualquer afirmação proposta.

As questões abordaram 08 temas agrupados em 02 eixos a seguir:

- Estrutural: aspectos arquitetônicos, financeiros, inserção urbana, infraestrutura e equipamentos públicos;

- Sociocultural: gestão condominial, sociabilidade e segurança.

Eixo Estrutural: aspectos arquitetônicos, financeiros, inserção urbana, infraestrutura e equipamentos públicos

Sob o eixo "estrutural" levantaremos as questões que dizem respeito à estrutura do PMCMV. Verificando qual é o impacto desses aspectos e como eles estão relacionados com as causas de abandono dos imóveis.

Assim, foram analisados os seguintes aspectos: arquitetônicos, financeiros, inserção urbana, infraestrutura e equipamentos públicos.

O primeiro a ser analisado diz respeito aos aspectos arquitetônicos referentes a qualidade, tamanho, configuração dos cômodos do apartamento e sua implantação (Figura 5). 
Pelo resultado da pesquisa, é possível observar que os aspectos arquitetônicos são poucos relevantes quando se trata dos motivos que levaram as famílias a saírem do condomínio. Seja pela satisfação das famílias em possuírem uma moradia nova e adequada, ou porque ainda é cedo para avaliar a durabilidade dos materiais empregados, já que os empreendimentos do estudo de caso foram entregues há no máximo 03 anos.

Mesmo assim, há diversos relatos de síndicos e moradores que afirmaram a existência de uma série de patologias desde o momento da entrega dos empreendimentos. Muitas delas são em decorrência da baixa qualidade dos materiais empregados e/ou dos erros de execução.

Apesar das diversas reclamações relatadas tanto nas pesquisas, quanto no registro das reuniões com o síndico ou assembleias de condomínio, poucos afirmam que a saída das famílias foi motivada por problemas construtivos no imóvel.

Referente ao tamanho e à quantidade de cômodos dos apartamentos, a pesquisa apontou que o projeto padrão da unidade com sala, cozinha e dois dormitórios foi pensado em uma família típica, formada pelo casal e 02 filhos, porém percebe-se que parte das famílias dos empreendimentos não são atendidas pela unidade proposta e infelizmente a diversidade da composição familiar não é respeitada no desenvolvimento dos projetos.
A família da Dona J. era grande, lá morava ela, a sogra, o marido e os quatro filhos. No começo até se deu um jeito. Ela fez da sala mais um quarto e ali jogava uns colchões à noite. Mas isso não durou muito tempo, logo um dos filhos mais velho foi morar com a mãe da Dona J., que vivia lá no Banhado, na favela de onde eles vieram. Ela sempre reclamava de ter deixado a Prefeitura demolir sua casa lá. Dizia que a casa não era bonita como o apartamento, mas era mais espaçosa e sempre tinha a chance de fazer um puxadinho aqui e outro ali, e assim ia aumentando o tamanho. Agora que o filho tá trabalhando, disse que vai construir outro barraco lá. Começar aos pouquinhos, quem sabe não volta pra lá (...) (Moradora do Colônia Paraíso II).

Confirmando o que diz Ferreira (2012), que como o mote do PMCMV é uma perspectiva quantitativa, deixou para segundo plano os aspectos de qualidade arquitetônica e dos impactos urbanos da produção das unidades habitacionais. Assim seguiram-se as incontáveis repetições de padrões arquitetônicos, de forma a atender às exigências do programa e manter o maior lucro possível para as construtoras, sem se preocupar em atender ou se adequar da melhor forma possível à realidade das famílias beneficiárias.

Além da repetição das tipologias, outro agravante é a impossibilidade de rearranjo da unidade para atender a seus novos moradores, já que, além de serem verticalizadas, as edificações são construídas em alvenaria estrutural que impede a remoção de qualquer parede. 
Este desafio foi proposto no quarto eixo estrutural do PlanHab, cujo objetivo era ampliar a produção, estimular e fomentar a modernização da cadeia produtiva da construção civil voltada à produção de Habitação de Interesse Social e à habitação do mercado popular. Buscando obter qualidade, menor custo, ganho de escala e agilidade, desonerando o processo de produção e simplificando o processo de licenciamento habitacional. (BRASIL, 2009)

Para tanto, o PlanHab pregava a importância da interação do setor público com universidades e centros de pesquisa, junto ao qual se articularia uma rede de instituições tecnológicas para estabelecer padrões técnicos e para a utilização dos diversos insumos da produção habitacional (mão de obra, projetos, materiais e métodos construtivos), como para a assistência técnica à gestão e produção.

Porém, esses objetivos jamais saíram do papel e as medidas destinadas à modernização do setor da construção civil com identificação das inovações tecnológicas foram arquivadas.

O terceiro aspecto da pesquisa, as dificuldades financeiras para pagar os custos com a nova moradia, demostra que eles falam muito mais alto que os aspectos arquitetônicos, já que o tema "custo da habitação" correspondeu a mais de $50 \%$ das causas de as famílias deixarem a tão sonhada casa própria.
Foi observado que o valor da prestação, aparentemente irrisório, aliado aos custos da taxa de condomínio, água, energia elétrica e gás, impõe às famílias acostumadas a acessar os serviços básicos através de ligação clandestina, a ir morar em um condomínio com todas as suas dinâmicas financeiras e social.

Eu pergunto... Porque ter no condomínio 35 famílias com renda zero, porque a Prefeitura $e$ a CAIXA colocam essas famílias em condomínio se elas não tem como pagar as suas despesas? (Morador do Colônia II, desabafo em reunião conjunta entre CAIXA e Prefeitura de São José dos Campos).

Com certeza a preocupação do morador identificado acima, deveria ser uma preocupação do poder público, pois somente as custas com a taxa de condomínio dos empreendimentos do estudo de caso variam de $\mathrm{R} \$ 96,81$ a $\mathrm{R} \$ 135,96$, ou seja, aproximadamente $15 \%$ do salário mínimo (data base de 2016).

Infelizmente, é possível ver claramente mais uma situação já prevista no PlanHab, mas desconsiderada, que é a definição dos grupos de atendimento, cuja composição do "Grupo 1" era de famílias sem renda ou com renda líquida abaixo da mínima necessária à capacidade de assumir um compromisso de retorno regular e estruturado, devendo ser considerado investimento a fundo perdido, ou seja, integralmente subsidiado. 
Assim, observa-se um alto índice de inadimplência tanto na prestação, quanto no condomínio, e um movimento de retorno para áreas de origem, com a venda ou locação dos imóveis.

A M. veio lá da Comunidade do Sapê, depois que mudou pra cá passou muitas dificuldades financeiras, pois vivia de coleta e venda de reciclagem, mas por não poder mais guardar seu material, agora ela e o marido estão desempregados. Pra sobreviver começou a vender mandioca, enquanto o marido tenta arrumar algum emprego, ou coletar algum material reciclável. Deixava muitas vezes seu filho de 04 anos sozinho. E que por isso tem sido acompanhada pelo conselho tutelar pelas questões de negligência com a criança. Não aguentou muito tempo essa vida, quando teve a oportunidade de ir embora, vendeu seu apartamento e foi morar de favor no fundo da casa da sogra.

Sabe, uma coisa que desanima as famílias é o custo de vida, ficou muito caro morar ali dentro. E o pior, isso é pra sempre, não é igual a prestação que um dia acaba, o condomínio é pra sempre. (Sindico)

Porém, cabe destacar que a inadimplência não é uma condição somente dos moradores da área de risco, mas para todas as famílias do condomínio que passam por alguma crise financeira, mesmo que momentânea.

A moradora buscou o atendimento social pra tentar conseguir algum apoio assistencial. Falou que estava passando por um problema grave de saúde e que não podia trabalhar, atualmente estava vivendo com somente $\mathrm{R} \$ 400,00$ do Bolsa Família, pra ela e seus dois filhos. Não tinha condição de pagar as dívidas. Tentou negociar várias vezes o condomínio, mas nunca conseguia cumprir os acordos. Ela disse que sabe que está a ponto de perder o apartamento, porque deve muitos meses pra CAIXA. Está tentando negociar com alguém pra alugar o apartamento, nem que for só pra pagar a prestação e ter um dinheirinho a mais. Enquanto isso vai voltar pra casa da mãe, até que melhore de saúde e volte a trabalhar. Disse que gosta daqui e quando der vai voltar. (Relato da assistente social sobre uma moradora que alugou o apartamento).

Esta é uma das muitas situações na qual o morador perde a principal fonte de renda, e se vê sem trabalho e sem ter como manter os pagamentos da moradia.

É fato que a dinâmica financeira é uma das que mais motiva a saída dessas famílias do condomínio. Elas saem de uma situação informal, a baixo custo, para uma moradia legal, porém de alto custo, se comparado às suas condições financeiras.

Nas pesquisas, pode-se perceber que os aspectos de inserção urbana e mobilidade é pouco determinantes para as causas de abandono, pois essas famílias em sua grande maioria já moravam nas "franjas" da cidade, em bairros que possuíam a mesma carência de equipamentos públicos.

E a distância dos empreendimentos até o polo central do município de São José dos Campos, 
também não foi considerada como uma dificuldade, uma vez que próximo dos condomínios, a no máximo $2 \mathrm{~km}$, foram identificadas centralidades com bancos, comércios e serviços que atendem às necessidades dos moradores dos empreendimentos do estudo de caso.

Em relação a infraestrutura, foi comprovado que todos os empreendimentos do estudo de caso são dotados de infraestrutura urbana básica, como água, esgoto, iluminação pública e coleta de lixo.

Desse modo, é possível observar que na maioria dos casos, o benefício de possuir a casa própria se sobrepõe às dificuldades enfrentadas, já que os longos deslocamentos, a dificuldade de transporte público, problemas de vagas em escola ou de atendimento nos postos de saúde, já eram vivenciados por esta população.

Esse contentamento forçado favorece ao poder público a prática de se manter inerte frente à localização dos empreendimentos, e permite às construtoras escolherem terrenos levando em consideração somente o barateamento do custo das unidades habitacionais, visando um lucro ainda maior.

E mais uma vez é possível identificar o não atendimento do PlanHab. Agora especificamente sobre o segundo eixo, que tem por objetivo justamente garantir acesso à terra urbanizada, legalizada e bem localizada para a provisão de habitações de interesse social. Convém enfatizar a importância da regularização de assentamentos informais, garantindo-se a permanência dos moradores de baixa renda. Como consequência, tem-se que a terra seja parte estrutural da política de habitação, assumindo como princípio a implementação dos instrumentos de reforma urbana que possibilitam melhor ordenamento e maior controle do uso do solo, de forma a combater a retenção especulativa e garantir acesso à terra urbanizada, fazendo com que a propriedade urbana cumpra sua função social. (BRASIL, 2009). Pois, como diz ROLNIK (2010), A perspectiva coletiva do melhor uso do imóvel dentro da cidade é o que transforma a busca da função social da propriedade em realidade.

\section{Eixo sociocultural: gestão condominial, sociabilidade e segurança}

Levando em consideração que um programa habitacional não termina simplesmente quando as moradias são entregues, o PMCMV assumiu a responsabilidade de também entregar empreendimentos capazes de promover a sustentabilidade social, econômica e ambiental de seus beneficiários.

A questão toda, como é possível observar na análise do eixo sociocultural, é o desafio de encontrar mecanismos que executem o alinhamento das políticas urbanas, sociais e 


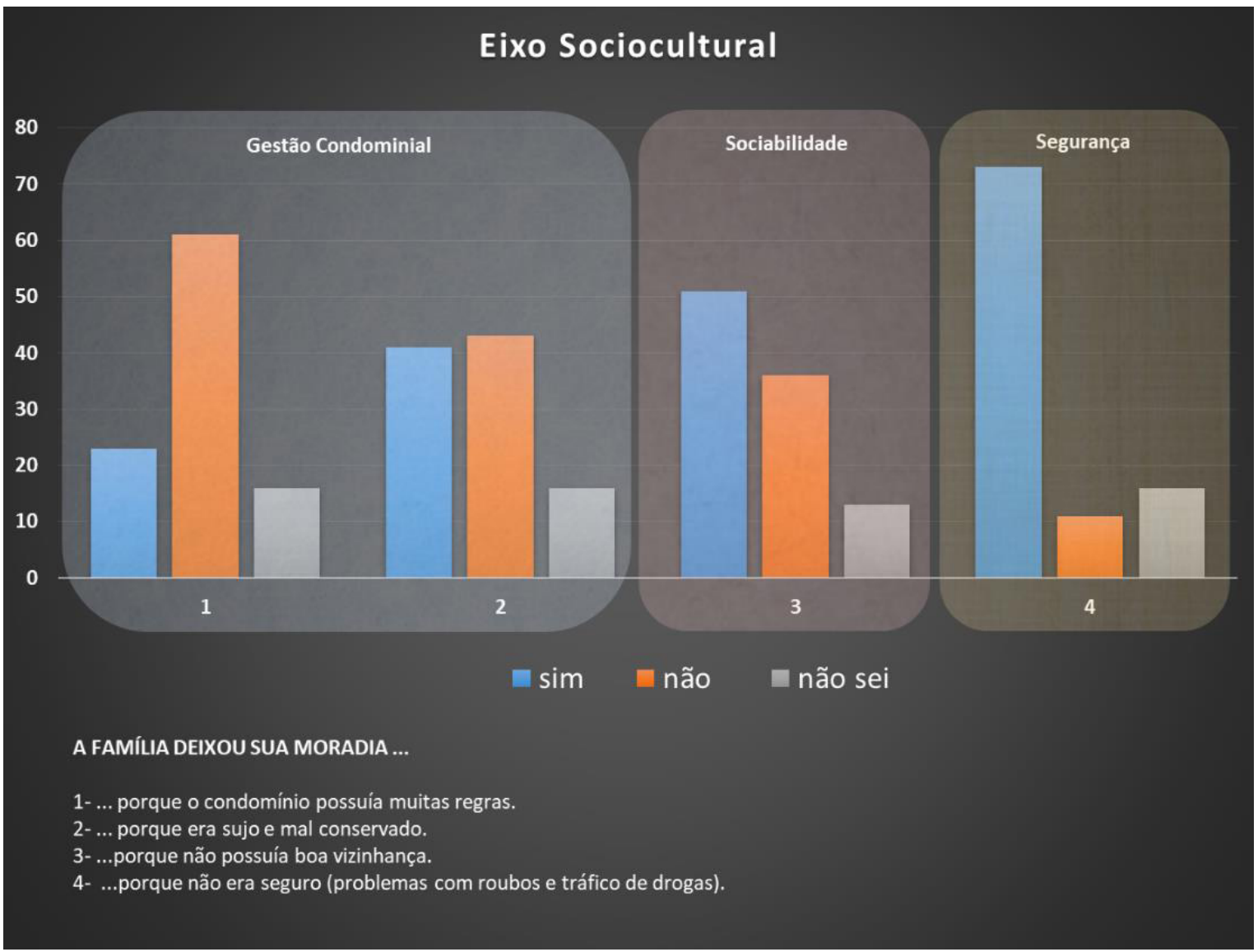

Figura 5. Eixo Estrutural: gestão condominial, sociabilidade e segurança como causa de abandono, venda ou aluguel do imóvel dos empreendimentos Colônia Paraíso II, Alto da Ponte e Colinas 2. Fonte: Pesquisa com os síndicos (jun/2018). Elaborado pela autora. habitacionais, de forma que as famílias se sintam incluídas e não desejem abandonar sua moradia (Figura 6).

Uma questão constantemente abordada nas reuniões com os síndicos, assembleias com os moradores e até mesmo nos atendimentos sociais é o modelo de gestão condominial.

Os modelos seguidos pelas construtoras são inspirados em condomínios do PMCMV - Faixa 2 e 3 , onde não há nenhuma tentativa de integrar as pessoas, formar liderança dentre os condôminos ou procurar alternativas que reduzam as despesas de condomínio. Portanto, este modelo é totalmente inadequado às necessidades e características do público alvo do PMCMV - Faixa 1, que necessita de ferramentas para facilitar o convívio e a sociabilidade entre as famílias e o bairro, tendo em vista que muitas vezes esses beneficiários são realocados há vários quilômetros de sua moradia original, tendo ainda que se a adaptar não só aos novos vizinhos, as regras do condomínio, mas também a estrutura do novo bairro.

A constituição em condomínios também reforça a ideia de um espaço privado e geralmente com um único acesso. Essa configuração traz uma ilusão de que o condomínio é seguro e com espaços comuns para o lazer das famílias, mas seus projetos são bem diferentes dos apresentados para a classe média. 
Esses espaços comuns, infelizmente, são vistos como custo, pois trazem às famílias de baixa renda a responsabilidade da manutenção de ruas, gramados, iluminação e limpeza. Responsabilidade essa que, na sua moradia anterior, era do poder público.

Como se não bastasse todas essas responsabilidades, as famílias ainda se veem cercadas por regras de convivência que causam mudanças e muitas vezes traumas em seu modo de vida.

É aí que surge a figura do síndico, assumindo um papel de líder dessa população, porém sem a mínima preparação para exercer essa função de máxima responsabilidade. Desestruturando ainda mais a convivência e a sociabilidade no condomínio.

Infelizmente, mesmo com as ações de preparação da gestão condominial, previstas na segunda fase do PMCMV, de incentivar a autogestão na administração dos condomínios, promovendo ações voltada na formação, implantação, organização e gestão do condomínio, não se observa o surgimento de novas lideranças, e sim renúncias infindáveis de síndicos e subsíndicos.

Em todas as entrevistas realizadas com os síndicos o assunto inadimplência esteve em destaque quando se fala em gestão condominial. Muitos alegam que o percentual de inadimplência está acima de $60 \%$, impossibilitando o pagamento de despesas como portaria e limpeza, adiando indefinidamente a manutenção das áreas comuns. Mas como se demonstra na pesquisa, a má conservação dos condomínios não é tão relevante quando se trata das causas de mudança das famílias, pois como grande parte não paga o condomínio também não se veem no direito de exigir que ele esteja em bom estado.

Referente ao aspecto de sociabilidade, foi possível identificar na pesquisa com os síndicos as diversas situações nas quais a convivência das famílias causou conflito entre os moradores, devido à diversidade social.

Quando Dona S. veio pra cá achou que seria tudo organizado, que ia ser igual aqueles condomínios que a gente vê na televisão... Recebia sua aposentadoria e pagava tudo direitinho. Mas coitada, morava em frente o parquinho. Quer dizer, aquilo não era mais parquinho, era uma "biqueira". Toda vez Dona S. reclamava comigo pra dar um jeito naquilo. E eu falava: 'Como vou fazer isso? Se eu enfrentar eles, eles me matam. Não posso, não.'

E a cada dia Dona S., que tinha vindo tão feliz pra cá, ficava cada vez mais triste. Um dia o filho deu um jeito, tirou Dona S. daqui e alugou o apartamento. Ainda bem, que quem entrou, paga direitinho o condomínio. (Sindico).

Essa construção de elos de convivência e relação de confiança entre os moradores é um desafio a ser conquistado pelo Trabalho Técnico Social (TTS). Com o desenvolvimento 
de ações que visam facilitar a adaptação das famílias beneficiárias à nova moradia, tendo um acompanhamento efetivo da integração destas famílias para realidade de viver em condomínio.

Porém, infelizmente, como pudemos observar nos relatórios, o TTS nos empreendimentos do estudo de caso, limitaram-se a realizar algumas poucas reuniões, atividades esportivas e oficina com as crianças. Muito diferente do que preconiza a Instrução Normativa $n^{\circ} 8$ de 26 de março de 2009:

Um conjunto de ações que visam promover a autonomia, o protagonismo social e o desenvolvimento da população beneficiária, de forma a favorecer a sustentabilidade do empreendimento, mediante a abordagem dos seguintes temas: mobilização e organização comunitária, educação sanitária e ambiental e geração de trabalho e renda. (MCIDADES, 2009)

Encerrando o estudo das causas de abandono, venda e ou locação das moradias, interessa tratar de um ponto extremamente importante na gestão condominial que é o tráfico de drogas e os furtos constantes frequentes nos condomínios do estudo de caso.

O fato de o condomínio ser privado dificulta as investigações e a inibição do uso e tráfico de drogas, pois impede a polícia de entrar sem que tenha um mandato judicial. E dessa forma as áreas comuns do condomínio, que deveriam ter o papel de integrar, são vistas como locais perigosos.

A ação das milícias e do tráfico impedem a organização e a formação de liderança entre os moradores. E como sempre os síndicos são os mais afetados, pois sofrem pressão de todas as partes, seja para cumprir o regimento do condomínio ou para não entrar em conflito com o traficante, que tentam constantemente aliciá-los para favorecer o tráfico de drogas.

Dessa forma, a maioria dos moradores acaba adotando o entendimento de que o tráfico de drogas é um problema social e que ocorre em todo lugar. $E$ que ele só se transforma num problema quando tem ligação direta com a sua família.

Assim, o tráfico de drogas e a violência nos empreendimentos é uma das causas mais relevantes para o abandono da unidade habitacional.

Neste eixo, pode-se concluir que a dinâmica de condomínios para a população de baixa renda gera muitos descontentamentos, seja pelo custo da taxa condominial, que não traz retorno concreto para as famílias; seja pela necessidade do convívio social com a imposição de regras e normas coletivas; ou seja pela falta de segurança, mesmo se tratando de um condomínio fechado. 


\section{Conclusão}

É possível concluir que a realidade do PMCMV está muito distante do modelo definido pelo PlanHab, de uma política democrática, definida por meio de um planejamento moderno e com participação popular.

Diferentemente do que consta na lei e nas portarias que especificam o PMCMV, seus agentes se omitem ou se limitam, tendo uma participação pouco expressiva diante da dura realidade dos empreendimentos periféricos, dominados pelo tráfico de drogas e com um alto índice de inadimplência e abandono.

No município de São José dos Campos não foi diferente. Os empreendimentos seguiram gerenciados por construtoras que definiram a sua localização, como seriam os seus projetos e como seriam edificados, preocupando-se unicamente com a construção de casas, sem levar em conta as características do público alvo do PMCMV Faixa 1.

Durante os eixos levantados na pesquisa, por diversas vezes o modelo de produção de empreendimentos em condomínio foi apontado como justificativa para a falta de adaptação das famílias, talvez porque ele traz consigo o endividamento, a inadimplência, a falta de segurança, as regras de convivência e a segregação das famílias, muitas vezes levando-as a deixar suas moradias.
Sob o eixo estrutural, a pesquisa indicou as faIhas na regulamentação e especificação do programa, indicando que os aspectos financeiros são mais expressivos que os aspectos arquitetônicos. Assim, a principal causa que coloca em risco a permanência das famílias no condomínio é a dificuldade de se adaptarem ao custo dessa nova moradia, que resultou em despesas como: o valor da prestação, a taxa de condomínio, os consumos de água, energia elétrica e gás.

Desta forma, foi identificada a necessidade da criação de ferramentas que auxiliem essas famílias nos momentos de vulnerabilidade social, preparando-as para superar esses obstáculos financeiros.

Outra possibilidade seria debater novas estratégias que não se resumam ao direito de propriedade, mas sim ao direito de moradia, se adequando com a realidade de cada família.

Observou-se que essas dificuldades financeiras também refletem diretamente na gestão condominial, ocasionando, conforme relatado pelos síndicos, um alto índice de inadimplência do condomínio, tornando o valor arrecadado insuficiente para pagamentos das despesas.

E assim os síndicos seguem perseguindo o desafio de diversos rearranjos para adequar a gestão condominial com a realidade das famílias do condomínio. Buscam alternativas para redução 
da taxa do condomínio através da tarifa social e negociações de dívidas com concessionárias, eliminando serviços não essenciais para manutenção do condomínio, ou infelizmente, obtendo benefícios em troca de favores aos traficantes ou milícias instauradas nos condomínios. Além disso, os síndicos ainda esbarram na responsabilidade de dar solução a grande quantidade de conflitos sociais, devido à diversidade social dos moradores. Esse problema poderia ser sanado com a realização de um TTS de qualidade, de forma a garantir a capacitação dos síndicos e a criação de elos de convivência e relação de confiança entre as famílias.

A solução de condomínio fechado por muros, que hipoteticamente deveria trazer segurança, infelizmente internalizou a violência, impedindo que a segurança pública entre em um condomínio privado.

Apesar de todas as críticas e dificuldades apresentadas nas pesquisas, a propriedade ainda é vista pelas famílias como garantia de patrimônio, pois trazem a expectativa de que o bem um dia poderá ser capitalizado ou convertido como herança para os filhos.

Mas não podemos desconsiderar que a transferência do imóvel para outra pessoa, muitas vezes por valores insignificantes, já que houve o aproveitamento dos subsídios concedidos, desvia o objetivo social do programa, pois acaba beneficiando famílias de maior renda.

Assim, é certamente questionável a produção de moradias em condomínios verticais para famílias de baixa renda, em função do impacto que este modelo produz na vida dessas famílias.

É preciso divulgar e sensibilizar os gestores públicos, Ministério das Cidades, Secretarias Municipais de Habitação, Prefeitos e CAIXA de que esse modelo não está plenamente adequado a todos os tamanhos, composição e origens familiares, e que não é possível planejar um único modelo para uma população tão diversa.

Esta constatação levanta as discussões sobre novas formas de acesso à moradia que não seja a propriedade. E que outras opções devem ser estudadas para permitir novos rearranjos que atendam principalmente a população com renda inferior a um salário mínimo, seja mediante propriedade coletiva, arrendamento ou locação social.

Um único programa habitacional estruturado em condomínios verticais, não é, nem pode ser a solução para as diferenças culturais, econômicas e sociais. Não há como padronizar a composição familiar e consequentemente não há como atender necessidade distintas com a mesma solução. É preciso refletir sobre outras alternativas para essa população. 


\section{Referências}

BRASIL. Lei no 11.977, de 7 de Julho de 2009a. Disponível em: <http://www.planalto.gov.br/ ccivil_03/_ato2007-2010/2009/lei/l11977.htm>. Acesso em: 2018.

BRASIL, Instrução Normativa no 8, de 26 de Março de 2009d. Disponível em: <http://www. caixa.gov.br/site/paginas/downloads.aspx> Acesso em: 2018.

BRASIL. Plano Nacional de Habitação. Brasília. Ministério das Cidades, dezembro 2009. Disponível em: <http://bibspi.planejamento.gov. br/bitstream/handle/iditem/285/Publiicacao_PlanHab_Capa.pdf?sequence $=1$ \&isAllowed $=y>$. Acesso em: dez. 2017.

CARDOSO, A. L. (org.). O programa Minha Casa Minha Vida e seus efeitos territoriais. Rio de Janeiro: Letra Capital, 2013. 322p.
FERREIRA, J. S. W. (Coord.). Produzir casas ou construir cidades? Desafios para um novo Brasil urbano. São Paulo: LABHAB: FUPAM, 2012. 202p.

MARICATO, E. Brasil, cidades: alternativas para a crise urbana. Petrópolis: Vozes, 2001. 208p.

ROLNIK, R.; KLINTOWITZ D.; REIS J.; BISCHOF R. Como produzir moradia bem localizada com os recursos do Programa Minha Casa Minha Vida? Implementando os instrumentos do Estatuto da Cidade! Rio de Janeiro: Letra Capital: Observatório das Metrópoles, 2010. 136p.

RUFINO, M. B., Um olhar sobre a produção do PMCMV a partir de eixos etnográficos. In: AMORE, C. S.; RUFINO, M.; SHIMBO, L.Z. (orgs.). Minha casa...E a cidade? Avaliação do Programa Minha Casa Minha Vida em seis estados brasileiros. Rio de Janeiro: Letra Capital, 2016, p. 51-70 